\section{Transfer of behavior controlled by an imprinted stimulus via brain homogenate injections in turkeys}

\author{
ALLAN H. SCHULMAN \\ Virginia Polytechnic Institute and State University, Blacksburg, Va. 24061
}

Operant keypecking, in order to view an imprinted stimulus, was greater in turkeys receiving injections of brain homogenates from similarly trained Ss when compared to birds receiving control injections. The observed transfer effect cannot be explained in terms of a general activity increase and is therefore assumed to be specific to the task. Moreover, the data suggest that such developmentally important behaviors as imprinting may be useful in the study of the biochemistry of behavior.

Numerous studies have reported transfer of response biases from one organism to another by means of injections of brain material (Babich, Jacobson, Bubash, \& Jacobson, 1965; Fjerdingstad, Nissen, \& Roigaard-Petersen, 1965; Ungar, 1967; Golub \& McConnell, 1968; Golub, Masiarz, Villars, \& McConnell, 1970 Braud, 1970); however, the reliability of the effect remains controversial (Gross \& Carey, 1965; Gordon, Deanin, Leonhardt, \& Gwynn, 1966; Branch \& Viney, 1966; Luttges, Johnson, Buck, Holland, \& McGaugh, 1966). While failures to replicate the effect may indicate that it is either a procedural artifact or paradigmatically specific, an alternative possibility is that both the organism and the behavior chosen for study are less than appropriate. In contrast to adult rodents (the organisms typically studied), neonatal precocial birds may be better suited for the biochemical study of behavior in vertebrates because (1) they have a weakly developed blood-brain barrier (Lajtha, 1957; Spooner \& Winters, 1967) and (2) during this stage of development, environmental stimuli can predictably be expected to exert profound and long-lasting effects upon the object preferences of the animals by means of a genetically controlled process (Graves \& Siegel, 1968, 1969) termed imprinting. In addition, Bateson, Horn, \& Rose (1969) and Smith, Nott, \& Yarwood (1970) have shown recently that imprinting produces reliable biochemical differences in the brains of chicks. Because of the physiological and behavioral advantages provided by studying precocial birds, the present experiment was performed in order to determine whether a response controlled by an imprinted stimulus could be transferred from one animal to another by means of brain homogenate injections. posthatching days, imprinted-donor $\mathrm{Ss}$ were placed in the apparatus for four 15-min trials per day, at which time they were given continuous visual access to the imprinting stimulus. On Day 3 , and continuing until Day 10 these Ss were required to peck a 2-cm-diam disk located on one wall of the apparatus in order to effect a 15 -sec presentation of the imprinting stimulus during a single 30 -min trial. In order to maximize the probability of pecking behavior during the test sessions, birds were tested when they were $12 \mathrm{~h}$ food deprived beginning on Day 4.

Control-donor Ss were treated in a similar manner; however, the imprinting stimulus was never presented to this group. On each of the first 2 posthatch days, birds were placed in the empty imprinting apparatus for four 15 -min trials. On Day 3 , and continuing until Day 10 , their keypecking behavior resulted in a momentary $(0.25 \mathrm{sec})$ offset of the chamber lights. Control-donor Ss were run when they were $12 \mathrm{~h}$ food deprived beginning on Day 4 .

In addition to pecking behavior, general activity of all Ss was recorded by a phonograph cartridge transducer located in the floor of the apparatus, whose digitized output was fed into an electromechanical counter.

On Day 14, all Ss were sacrificed by means of decapitation. The forebrain (excluding optic tectum and cerebellum) of each $\mathbf{S}$ was removed and homogenized in an ice bath, together with $1 \mathrm{cc}$ physiological saline. Within $10 \mathrm{~h}$ after hatching, recipient

Ss were injected intraperitoneally with
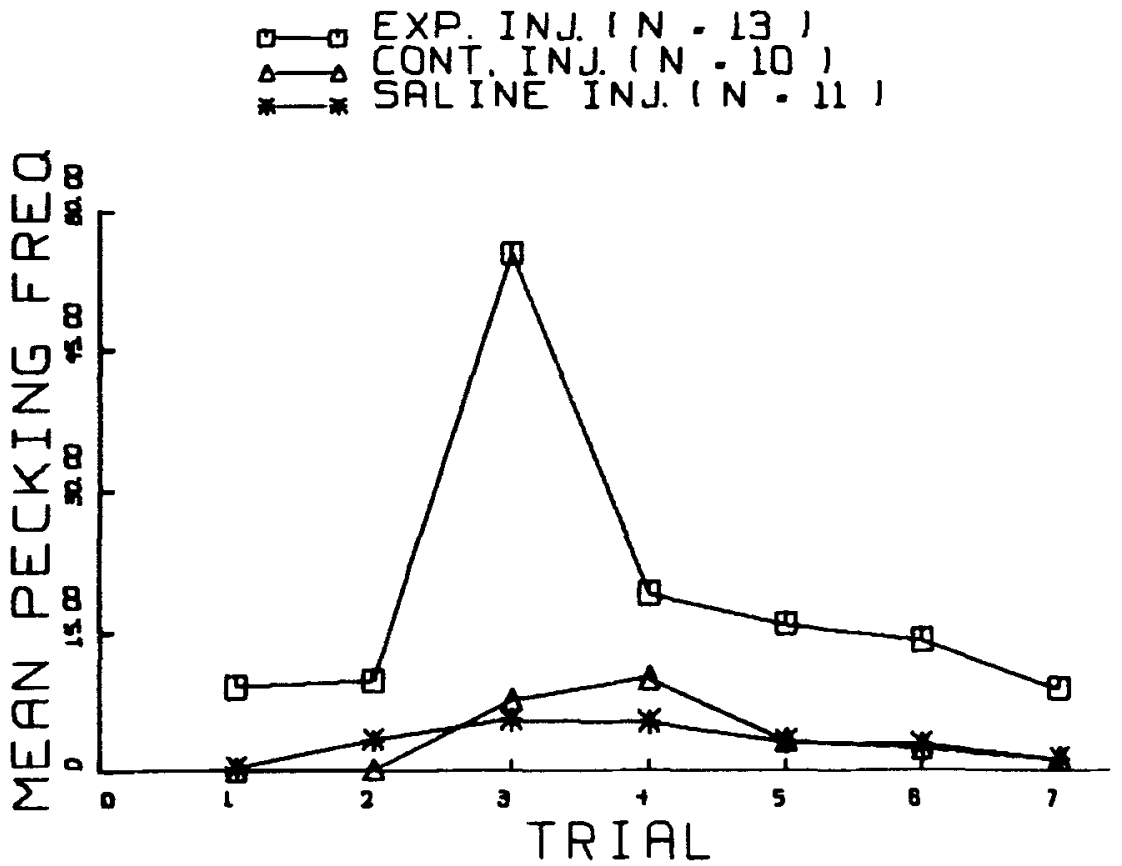

Fig. 1. Mean pecking rate per daily 30-min trial for three groups of injected turkeys. Each peck resulted in a 15-sec presentation of the imprinted stimulus. Twelve hours of food deprivation was instituted beginning on Trial 2 . 

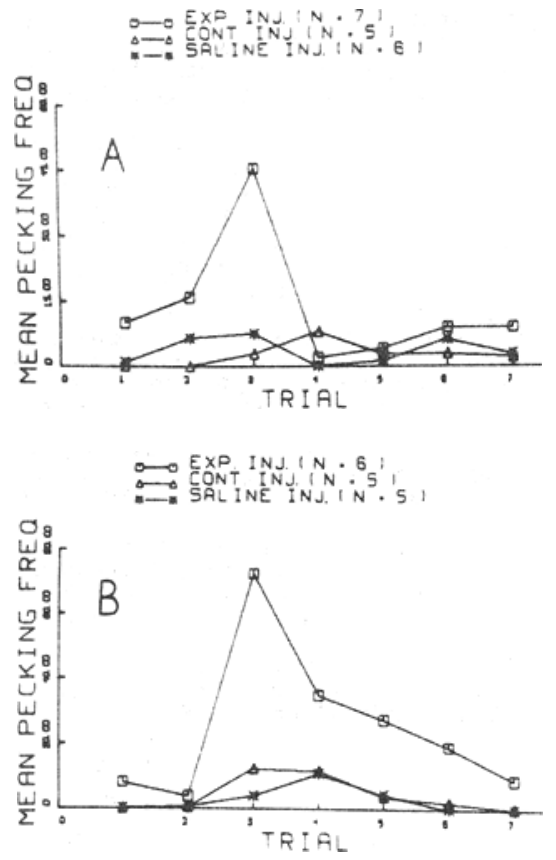

Fig. 2. Mean pecking rate per daily 30-min trial for three groups of injected turkeys: (a) first replication; (b) second replication. Each peck resulted in a 15-sec presentation of the imprinted stimulus. Twelve hours of food deprivation was instituted beginning on Trial 2.

$1 \mathrm{cc}$ of the homogenate. In addition to Ss receiving brain material from imprinted donors and control donors, a third group of $S s$ received 1-cc intraperitoneal injections of saline alone. Twelve hours after injection, all recipient Ss commenced imprinting training. The only difference in training procedure between recipient Ss and the imprinted donors was that, for the former group, the period of continuous exposure to the imprinting stimulus was reduced from four 15-min sessions to two 15 -min sessions on the first 2 posthatch days in order to maximize any potential treatment differences resulting from injection. All recipient $\mathrm{Ss}$ were run without the animal testers' knowing the nature of the injected material. RESULTS

Among the 23 donor $\mathrm{Ss}$, the rate of pecking of birds viewing the imprinted stimulus ( $\overline{\mathrm{X}}=167.8)$ was consistently greater than that of the control Ss $(\bar{X}=75.8)$. This difference in pecking performance was statistically reliable $(\mathrm{t}=1.74, \mathrm{df}=21, \mathrm{p}<.05)$ and thus confirms the observations of other investigators (Peterson, 1960; Hoffman, Searle, Toffey, \& Kozma, 1966), indicating that operant control over imprinted behavior may be achieved in turkeys as well as ducklings and chicks (Bateson \& Reese, 1969). The pecking behavior of recipient $S s$ is shown in Fig. 1. Whereas the difference in the predeprivation pecking behavior of the three groups was significant $(F=3.43$, $\mathrm{df}=2 / 31, \mathrm{p}<.05)$, an analysis of postdeprivation performance on Trials 2-7 revealed a very significant trials effect $(F=2.90, \mathrm{df}=5 / 155$, $\mathrm{p}<.025$ ) and a significant Trials by Treatment interaction $(F=2.04$, $\mathrm{d} f=10 / 155, \quad \mathrm{p}<.05)$, thereby indicating that, while pecking behavior varied significantly over trials, birds in the group which received "imprinted" brain material accounted for most of the change. Further analysis of the Trials by Treatment interaction over Trials 2-7 revealed that the imprinted-injected group differed significantly from the control-injected group $(F=2.29, \mathrm{df}=5 / 105, \mathrm{p}<.05)$ and the saline-injected group $(F=3.02, \quad d f=5 / 110, \quad p<.025)$. These latter two groups, however, did not differ significantly from each other $(\mathrm{F}<1)$.

Operant pecking behavior drops rather dramatically after Trial 3 (Posthatch Day 5) in the imprinted-recipient group. This finding parallels Christopher's (1969) observations that the following responses of turkeys tested in the imprinting situation tends to peak at this age.

The data presented in Fig. 1 represent the combined results of two independent replications. There were no significant differences between these replicates, and the phenomenon observed is highly reliable (Fig. 2).
An analysis of general activity revealed no significant differences among the three groups $(p>.05)$. All groups showed a significant increase in activity over trials following deprivation which peaked between Trials 2 and $4(F=4.69$, df $=5 / 155$, $\mathrm{p}<.01$ ) (Fig. 3).

\section{DISCUSSION}

The results of this study suggest that behavior controlled by an imprinted stimulus may be transferred from one animal to another via brain homogenate injections. Turkeys receiving brain material from trained donors exhibited the operant response associated with viewing an imprinted stimulus to a greater extent than did control-recipient Ss. Although the transfer effect became most apparent after food deprivation, it is not known at present whether deprivation is a necessary prerequisite for the effect. The question of whether this response bias is specific to the imprinted stimulus also remains unanswered; however, failure to obtain reliable activity differences among three injected groups suggests that the present transfer effect may be interpreted as one of a specific response rather than resulting from a general increase in activity.

Furthermore, the data suggest that developmentally relevant behavioral sequences under strong genetic control such as imprinting may be particularly well suited for the study of the biochemistry of behavior.

\section{REFERENCES}

BABICH, F. R., JACOBSON, A. L.,
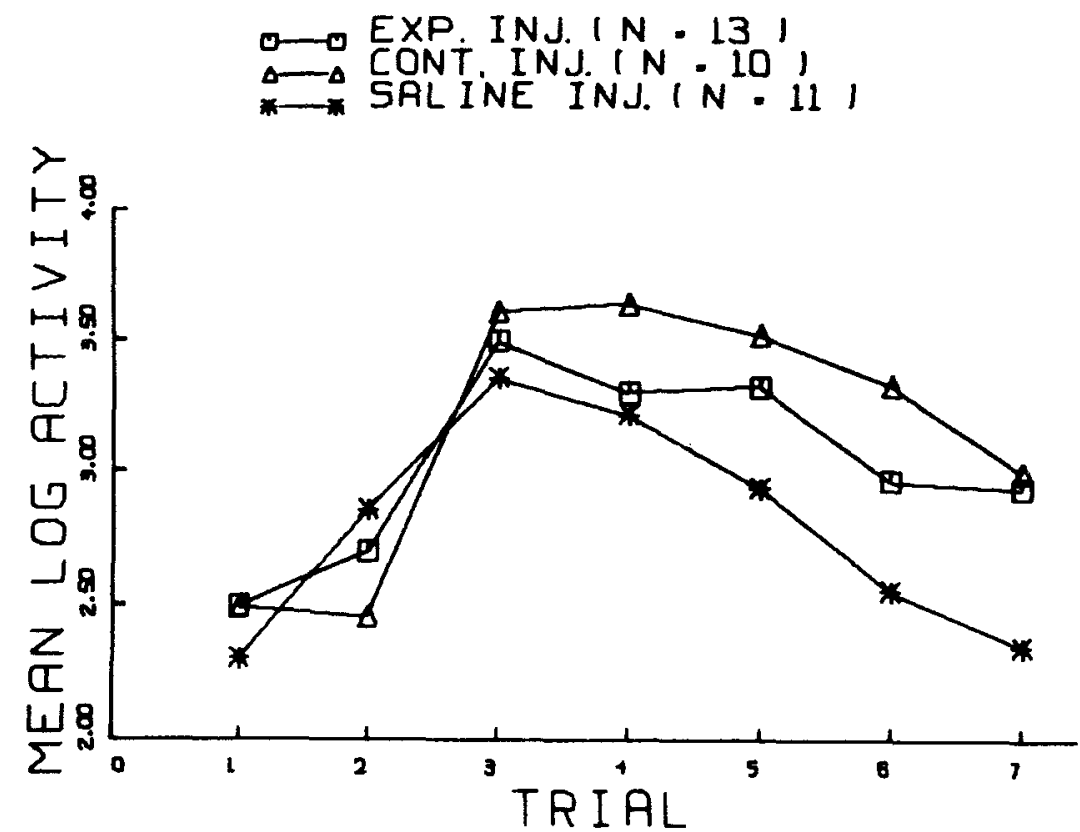

Fig. 3. Mean log activity score per daily $30-\mathrm{min}$ trial for three groups of injected turkeys. Twelve hours of food deprivation was instituted beginning on Trial 2. 
BUBASH, S., \& JACOBSON, A. Transfer of a response to naive rats by injection of RNA extracted from trained rats. Science, $1965,149,656$.

BATESON, P. P. G., HORN, G., \& ROSE, S. P. R. Effects of an imprinting procedure on regional incorporation of tritiated lysine into protein of chick brain. Nature, $1969,223,534-535$.

BATESON, P. P. G., \& REESE, E. The reinforcing properties of conspicuous stimuli in the imprinting situation. Animal Behaviour, 1969, 17, 692-699.

BRAUD, W. G. Extinction in goldfish: Facilitation by intracranial injection of RNA from brains of extinguished donors. Science, 1970, 168, 1234-1236.

BRANCH, J. C., \& VINEY, W. An attempt to transfer a position discrimination habit via RNA extracts. Psychological Reports, $1966,19,923-926$

CHRISTOPHER, S. B. Effects of age and social experience on imprinting in domestic turkeys and chickens. Unpublished doctoral dissertation, 1969 , The Pennsylvania State University.

FJERDINGSTAD, W. J., NISSEN, T., \& ROIGAARD-PETERSEN, H. H. Effect of ribonucleic acid extracted from the brains of trained animals on learning in rats. Scandinavian Journal of Psychology, $1965,6,1-5$.

GOLUB, A. M., MAISIARZ, F. R VILLARS, T., \& MCCONNELL, J. V. Incubation effects in behavior induction in rats. Science, $1970,168,392-394$.

GOLUB, A. M., \& McCONNELL. J. V Transfer of response bias by injection of brain homogenates: $A$ replication. Psychonomic Science, $1968,150,1749$.

GORDON, M. W., DEANIN, G. G., LEONHARDT, H. L., \& GWYNN, R. H. RNA and memory: A negative experiment. American Joumal of Psychiatry, 1966, 122, 1174-1178.

GRAVES, H, B., \& SIEGEL, P. B. Chicks' response to an imprinting stimulus: Heterosis and evolution. Science, 1968, $160,329.330$.

GRAVES, H. B., \& SIEGEL, P. B. Bidirectional selection for responses of Gallus domesticus chicks to an imprinting situation. Animal Behaviour, 1969, 17, 683-691.

GROSS, C. G., \& CAREY,F. M. Transfer of a learned response by $R$ NA injection: Failure of attempts to replicate. Science, $1965,150,1749$.
HOFFMAN, H. S., SEARLE, J. L.. TOFFEY, S \&OZMA F Behavioral control by an imprinted stimulus. Jourmal of the Experimental Analysis of Behavior. 1966, 9, 177-189.

LAJTHA, A. The development of the blood-brain barrier. Journal of Neurochemistry, 1957, 1, 216-227.

LUTTGES, M., JOHNSON, T., BUCK, C. HOLLAND, J. \& McGAUGH, J An examination of "transfer of learning" by nucleic acid. Science, 1966, 151 . 834-839.

PETERSON, N. Control of behavior by presentation of an imprinting stimulus. Science, $1960,132,1395-1396$.

SMITH, F. V., NOTT, K. H. \& YARWOOD, A. Brain protein synthesis and the approach response of chicks to a visual stimulus. Brain Research, 1970, 21. $79-90$.

SPOONER, C. E., \& WINTERS, W. D. Evoked responses during spontaneous and monoamine-induced states of wakefulness and sleep. Brain Research, 1967, 4, 189-205.

UNGAR, U. Transfer of acquired information by brain extracts. Journal of Biological Psychology, 1962, 9, 12-27. 